\title{
A Classification of Motivation and Behavior Change Techniques Used in Self- Determination Theory-Based Interventions in Health Contexts
}

Pedro J. Teixeira ${ }^{1}$, Marta M. Marques ${ }^{2}$, Marlene N. Silva ${ }^{1}$, Jennifer Brunet ${ }^{3}$, Joan Duda ${ }^{4}$, Leen Haerens ${ }^{5}$, Jennifer La Guardia ${ }^{6}$, Magnus Lindwall ${ }^{7}$, Chris Lonsdale ${ }^{8}$, David Markland ${ }^{9}$, Susan Michie $^{10}$, Arlen C. Moller ${ }^{11}$, Nikos Ntoumanis ${ }^{12}$, Heather Patrick ${ }^{13}$, Johnmarshall Reeve ${ }^{8}$, Richard M. Ryan ${ }^{8}$, Simon J. Sebire ${ }^{14}$, Martyn Standage ${ }^{15}$, Maarten Vansteenkiste ${ }^{5}$, Netta Weinstein $^{16}$, Karin Weman-Josefsson ${ }^{17}$, Geoffrey C. Williams ${ }^{18}$, Martin S. Hagger ${ }^{19,20}$

${ }^{1}$ University of Lisbon, ${ }^{2}$ Trinity College Dublin, ${ }^{3}$ University of Ottawa, ${ }^{4}$ University of Birmingham, ${ }^{5}$ Ghent University, ${ }^{6}$ Omada Health, ${ }^{7}$ University of Gothenburg, ${ }^{8}$ Australian Catholic University, ${ }^{9}$ Bangor University, ${ }^{10}$ University College London, ${ }^{11}$ Illinois Institute of Technology, ${ }^{12}$ Curtin University, ${ }^{13}$ Carrot, Inc, ${ }^{14}$ University of Bristol, ${ }^{15}$ University of Bath, ${ }^{16}$ Cardiff University, ${ }^{17}$ Halmstad University, ${ }^{18}$ University of Rochester, ${ }^{19}$ University of California, Merced, ${ }^{20}$ University of Jyväskylä

(C) 2020, American Psychological Association. This paper is not the copy of record and may not exactly replicate the final, authoritative version of the article. Please do not copy or cite without authors' permission. The final article will be available, upon publication, via its DOI: $10.1037 / \operatorname{mot} 0000172$

Full citation: Teixeira, P. J., Marques, M. M., Silva, M. N., Brunet, J., Duda, J., Haerens, L., La Guardia, J., Lindwall, M., Londsdale, C., Markland, D., Michie, S., Moller, A. C., Ntoumanis, N., Patrick, H., Reeve, J., Ryan, R. M., Sebire, S., Standage, M., Vansteenkinste, M., . . . Hagger, M. S. (2020). Classification of techniques used in self-determination theory-based interventions in health contexts: An expert consensus study. Motivation Science. https://doi.org/10.1037/mot0000172

\section{Author Note}

Martin S. Hagger's contribution was supported by a Finnish Distinguished Professor (FiDiPro) award from Business Finland (grant \# 1801/31/2105). Marta Marques' contribution was funded by the Marie-Sklodowska-Curie (EDGE) Fellowship programme (grant agreement No. 713567). We thank Eliana Carraça and Jorge Encantado for their contribution to the data synthesis. We have no known conflict of interest to disclose. Correspondence regarding this article should be addressed to Martin S. Hagger, SHARPP Lab, Psychological Sciences, University of California, Merced, 5200 N. Lake Rd., Merced, CA 95343, email: mhagger@ucmerced.edu 


\begin{abstract}
While evidence suggests that interventions based on self-determination theory have efficacy in motivating adoption and maintenance of health-related behaviors, and in promoting adaptive psychological outcomes, the motivational techniques that comprise the content of these interventions have not been comprehensively identified or described. The aim of the present study was to develop a classification system of the techniques that comprise self-determination theory interventions, with satisfaction of psychological needs as an organizing principle. Candidate techniques were identified through a comprehensive review of self-determination theory interventions and nomination by experts. The study team developed a preliminary list of candidate techniques accompanied by labels, definitions, and function descriptions of each. Each technique was aligned with the most closely-related psychological need satisfaction construct (autonomy, competence, or relatedness). Using an iterative expert consensus procedure, participating experts $(\mathrm{N}=18)$ judged each technique on the preliminary list for redundancy, essentiality, uniqueness, and the proposed link between the technique and basic psychological need. The procedure produced a final classification of 21 motivation and behavior change techniques (MBCTs). Redundancies between final MBCTs against techniques from existing behavior change technique taxonomies were also checked. The classification system is the first formal attempt to systematize self-determination theory intervention techniques. The classification is expected to enhance consistency in descriptions of selfdetermination theory-based interventions in health contexts, and assist in facilitating synthesis of evidence on interventions based on the theory. The classification is also expected to guide future efforts to identify, describe, and classify the techniques that comprise self-determination theory-based interventions in multiple domains.
\end{abstract}

Keywords: Self-determination theory interventions; Autonomous motivation; Autonomy support; Need satisfaction; Motivational technique 
A Classification of Motivation and Behavior Change Techniques Used in Self-Determination Theory-Based Interventions in Health Contexts

Chronic non-communicable diseases and conditions such as cancer, cardiovascular disease, obesity, and diabetes contribute to a large proportion of population morbidity and mortality worldwide, and also account for a substantive proportion of healthcare costs ( $\mathrm{Li}$ et al., 2018; OSBBR, 2016; The US Burden of Disease Collaborators, 2018). In response, national departments of health and healthcare organizations have advocated prevention through interventions to promote participation in health-related behaviors, such as participation in physical activity, healthy eating, avoiding tobacco, and treatment adherence (Dunton, Cousineau, \& Reynolds, 2010; Ueda et al., 2018; Wood et al., 2018). Given that current population-level participation in these behaviors is insufficient to confer health benefits and prevent chronic disease, developing behavioral interventions and testing their efficacy and effectiveness in increasing health behavior participation rates is considered a public health priority (Bartholomew \& Mullen, 2011; Glanz \& Bishop, 2010; Johnson \& Acabchuk, 2018). Psychologists and behavioral scientists have applied motivational theories to identify the modifiable factors and mechanisms that relate to health behaviors, which can be used as a basis for the development and evaluation of behavioral interventions (Hagger, Cameron, Hamilton, Hankonen, \& Lintunen, 2020; Rothman et al., 2015; Sheeran, Klein, \& Rothman, 2017). Self-determination theory (Deci \& Ryan, 1985, 2000; Ryan \& Deci, 2017) is a prominent theory of motivation that has demonstrated promise in identifying the psychological factors and processes that determine motivated behavior in diverse health contexts. In addition, interventions based on the theory have been shown to be efficacious in promoting motivation toward, and actual participation in, health behavior across multiple populations, contexts, and behaviors (e.g., Chatzisarantis \& Hagger, 2009; Emm-Collison, Jago, Salway, Thompson, \& Sebire, 2019; Gillison, Rouse, Standage, Sebire, \& Ryan, 2018; Ng et al., 2012; Teixeira, Carraca, Markland, Silva, \& Ryan, 2012; Williams, McGregor, Sharp, Kouides, et al., 2006; 
Williams, McGregor, Sharp, Levesque, et al., 2006). While there has been some previous research specifying and defining the content of self-determination theory-based interventions in education contexts (e.g., Aelterman et al., 2019; Cheon \& Reeve, 2013; Reeve \& Jang, 2006; Su \& Reeve, 2011; Tessier, Sarrazin, \& Ntoumanis, 2008), there have been few attempts to develop descriptions of the essential and distinct techniques that comprise interventions based on the theory (Gillison et al., 2018; Ryan, Patrick, Deci, \& Williams, 2008). Moreover, considerable variability in how the theory is currently applied and tested in health behavior settings has been noted (Silva, Marques, \& Teixeira, 2014). For example, interventions based on the theory have tended not to identify the theory-based constructs targeted by the intervention content, or clearly specify links between the content with the targeted constructs, or conduct appropriate analyses to test whether the intervention content leads to changes in both the construct and the outcome of interest, often a behavioral measure.

There is, therefore, a need to systematically identify and describe the practices or techniques that comprise self-determination theory-based interventions (Ryan et al., 2008). Identifying these techniques will be valuable to stakeholders (e.g., researchers, administrators) interested in developing behavioral interventions based on the theory and conducting research to establish their efficacy and effectiveness since it will provide a common set of descriptions of the techniques that make up the content of the interventions. It will also contribute to research aimed at developing an evidence base of optimally efficacious and effective intervention techniques based on the theory. The purpose of the present study was to develop an organized description of the essential techniques implemented within interventions based on self-determination theory in health contexts using an expert consensus approach.

\section{Self-Determination Theory and Basic Psychological Needs}

Self-determination theory is a theory of human motivation that has demonstrated efficacy in predicting motivated behavior in multiple contexts and populations, and for a variety of behaviors (Deci \& Ryan, 1985, 2000; Ryan \& Deci, 2017), including health 
behaviors such as physical activity, healthy eating, and smoking cessation ( $\mathrm{Ng}$ et al., 2012; Patrick \& Williams, 2012; Ryan \& Deci, 2017). Self-determination theory is unique among theories of motivation due to its focus on the quality of motivation rather than quantity alone. Self-determination theory emphasizes the importance of the kind of motivation that drives people's behavior, alongside considerations of how much they are motivated. Central to the theory is the distinction between self-determined or autonomous, and non-self-determined or controlled forms of motivation (Deci \& Ryan, 2000; Ryan \& Deci, 2017). These motivational subtypes reflect the degree to which actions are fully self-endorsed by the individual. Autonomous motivation reflects self-endorsed reasons for engaging in a behavior or pursuing a particular goal. Individuals acting for autonomous reasons experience their actions as freely chosen and consistent with their genuine sense of self, values, and personal goals, and feel that they are the origin of their actions (Ryan \& Deci, 2006). In contrast, controlled motivation reflects reasons for acting that are not self-endorsed. Individuals citing controlled reasons for action view their behavior as originating outside their self and feel that their actions are controlled by external contingencies (Sheldon \& Elliot, 1998; Sheldon et al., 2004). A third form of regulation is amotivation, a state which reflects a lack of any motivational force to act. Individuals who feel their actions are amotivated offer no discernible reason, motive, or intention for action (Deci \& Ryan, 2000; Ntoumanis, Pensgaard, Martin, \& Pipe, 2004). Across numerous health contexts, a cogent body of research has consistently found that autonomous forms of motivation are associated with behavioral persistence and healthier psychological outcomes (Hagger \& Chatzisarantis, 2015; Ng et al., 2012; Pihu, Hein, Koka, \& Hagger, 2008; Ryan \& Deci, 2017; Teixeira et al., 2012).

A further key premise of the theory is that the quality of motivation experienced by individuals when acting is determined by the extent to which they view their actions to be consistent with, and in the service of, three basic psychological needs - autonomy, competence, and relatedness (Deci \& Ryan, 2000; Ryan \& Deci, 2017). The needs are 
considered universal, and are implicated in the process that gives rise to the type of motivation experienced in behavioral contexts (i.e., hallmarks) of each of the three psychological needs. The need to experience autonomy reflects actions as freely chosen and self-endorsed, reflecting the need for individuals to experience a sense of ownership and responsibility over their actions. The need for competence refers to the experience of being effective in one's environment, mastering mentally or physically challenging tasks, and perceiving sufficient capacity to perform actions. The need for relatedness reflects the need to feel accepted and respected, and to gain a sense of connectedness and mutual concern with important others (Deci \& Ryan, 2000; Ryan \& Deci, 2017). A summary of the three basic psychological needs from the theory is provided in Table 1. Large-scale research has supported the primacy of the needs for autonomy, competence, and relatedness above other candidate needs (Sheldon, Elliot, Kim, \& Kasser, 2001) and across different cultural contexts (Chen et al., 2015). In addition, satisfaction of the needs have been shown to mediate the associations between autonomous motivation and behavioral persistence in multiple contexts including health behavior change (Ng et al., 2012). Analogously, the frustration of these basic psychological needs has been shown to mediate the associations between controlled forms of motivation and behavioral disengagement and lower wellbeing (Bartholomew, Ntoumanis, Ryan, Bosch, \& ThogersenNtoumani, 2011; Haerens, Aelterman, Vansteenkiste, Soenens, \& Van Petegem, 2015; Silva et al., 2014; Vansteenkiste \& Ryan, 2013).

Whether a person's psychological needs are satisfied or frustrated depends largely on the extent to which the person's surrounding environment and relationships support or thwart those needs (Deci, Eghrari, Patrick, \& Leone, 1994; Deci \& Ryan, 1985; Ryan \& Deci, 2017). The behaviors displayed, or messages provided, by social agents (e.g., health practitioners, teachers, coaches, parents, peers, family members and colleagues) operating in an individual's social environment, or the content of messages communicated by other means (e.g., leaflets, websites, text messages, smartphone 'apps'), can be more or less supportive or thwarting of the 
psychological needs. If the agents' behaviors or messages support the satisfaction of individuals' psychological needs, then these individuals are likely to experience their actions as autonomously motivated, and may engage with and/or maintain health behaviors (Deci \& Ryan, 2000; Ntoumanis, Quested, Reeve, \& Cheon, 2018; Ryan \& Deci, 2017). In contrast, behaviors and messages that do not support, or actively hinder, satisfaction of psychological needs likely undermine autonomous motivation and promote controlled forms of motivation or amotivation, which may lead to maladaptive outcomes and behavioral disengagement (Deci \& Ryan, 2000; Ntoumanis et al., 2018; Ryan \& Deci, 2017). Providing guidance on the behaviors displayed by social agents, and specifying the content of messages, are potentially effective means to promote autonomous motivation and sustained behavior change. The process by which these interventions affect the quality of motivation is through the satisfaction of the three basic psychological needs. Satisfaction of the needs is considered a key mediator of selfdetermination theory-based interventions on outcomes, particularly behavior change.

Ryan, Patrick, Deci, and Williams (2008) proposed an integrative process model that draws together the key components of self-determination theory. The model specifies the theory-based processes by which need supportive actions and messages, and other dispositional factors, relate to health behavior participation and outcomes. An adapted form of this model is presented in Figure 1. As specified in the model, social agents' (e.g., health practitioners, teachers, coaches, parents, peers, family members and colleagues) behaviors and messages that support autonomy, competence, and relatedness determine whether actors' basic psychological needs are supported or frustrated (path 1, Figure 1). The extent to which needs are satisfied or frustrated will determine the type of motivation experienced (path 2, Figure 1), and the extent to which the individual engages in, and persists with, health-related behaviors (path 3, Figure 1). The experience of actions as autonomous, controlled, or amotivated will also determine whether an individual experiences adaptive emotional outcomes and overall levels of satisfaction (path 4, Figure 1). Finally, the type of motivation experienced will determine the 
extent to which individuals report adaptive or maladaptive mental (path 5a, Figure 1) and physical (path 5b, Figure 1) health-related outcomes, respectively. Research has supported the proposed relations among the constructs of the process model, including relations between need-supportive interventions and need satisfaction, and between these interventions and behavioral and health-related outcomes (Ng et al., 2012; Su \& Reeve, 2011). There is also evidence demonstrating effects of interventions based on the theory on health behavior through need satisfaction and autonomous motivation, but tests of these mediating effects are relatively sparse (Chatzisarantis \& Hagger, 2009; Duda et al., 2014; Ng et al., 2012).

\section{Specifying the 'Techniques' of Self-Determination Theory Interventions}

As outlined in the previous section, the specific behavioral and communicative techniques can both signal and support basic psychological need satisfaction and, in turn, promote autonomous motivation. Often, interventions based on self-determination theory comprise a number of these techniques, and previous work has aimed to identify and catalogue these techniques. For example, research in the field of education has developed autonomy support training programs in which teachers are trained on the necessary skills and techniques to foster students' need satisfaction in classroom contexts (e.g., Aelterman et al., 2019; Cheon \& Reeve, 2013; Cheon, Reeve, \& Moon, 2012; Cheon, Reeve, \& Ntoumanis, 2018; Lonsdale et al., 2019; Reeve \& Jang, 2006; Reeve et al., 2014; Tessier, Sarrazin, \& Ntoumanis, 2010). Within the context of education, Reeve and Jang (2006) produced a list of instructional behaviors and lesson content that classroom teachers were observed to use to support autonomy. This list has been updated and organized according to whether the behaviors were autonomy-supportive or controlling (Reeve et al., 2014). Behaviors and instructions classified as autonomy-supportive were: taking the students' perspective, creating opportunities for student input and initiative, providing explanatory rationales for teacher requests, acknowledging and accepting expressions of negative affect, and displaying patience. Instructional behaviors considered to be controlling were: taking only the teacher's 
perspective, introducing extrinsic incentives, uttering directives without explanations, relying on pressuring language to silence students' complaints, and pushing students into immediate compliance with the teacher's agenda.

These descriptions have been incorporated into the training programs designed to develop autonomy-supportive behaviors in teachers and help them avoid the use of controlling behaviors. By intervening to change teachers' autonomy-supportive techniques, the programs are expected to promote students' autonomous motivation in class and, over time, better academic engagement and attainment. The techniques included in these programs have also been used in observational checklists to assess teachers' use of autonomy supportive strategies in class, and to assess changes in the use of more autonomy supportive strategies after their delivery. In addition, this approach has been used to describe autonomy supportive intervention content in multiple contexts (e.g. healthcare, education, the workplace, sport and coaching, parenting, and therapy) and guide development of future educational interventions based on self-determination theory (e.g., Aelterman, Vansteenkiste, Van den Berghe, De Meyer, \& Haerens, 2014; Carpentier \& Mageau, 2016; Froiland, 2015; Gagné \& Deci, 2005; Halvari \& Halvari, 2006; Jungert et al., 2015; McLachlan \& Hagger, 2010; Zuroff et al., 2007).

There is also research that has isolated techniques aimed at promoting motivation through support for competence and relatedness needs. Techniques to support competence focus on promoting a sense of satisfaction on tasks or toward goals, with a focus on making progress toward self-referenced goals, attaining mastery, and developing greater skills. For example, research has identified three essential techniques for competence support: stating clear expectations; providing 'how-to' guidance; and giving constructive/positive feedback. Studies have demonstrated the efficacy of these techniques in promoting motivation and adaptive outcomes (e.g., Carpentier \& Mageau, 2016; Jang, Reeve, \& Deci, 2010; Sierens, Vansteenkiste, Goossens, Soenens, \& Dochy, 2009; Tessier et al., 2010). A parallel line of research has focused on techniques that support relatedness. Research identified several 
essential techniques purported to support relatedness: fostering individualized conversation; promoting cooperation and teamwork; demonstrating awareness and care; and engaging in warm, friendly communication (Sparks, Dimmock, Lonsdale, \& Jackson, 2016; Sparks, Lonsdale, Dimmock, \& Jackson, 2017). Taken together, these research findings indicate sets of techniques that promote motivation and behavioral outcomes through support for autonomy, competence, and relatedness needs.

While numerous approaches to specifying the content of self-determination theory interventions exist, no formal system has been developed to identify and describe the techniques that comprise self-determination theory interventions. By comparison, relatively recent research has developed systems to identify, describe, and organize the essential techniques used in behavioral interventions more broadly. The development of classification systems for these techniques, referred to as behavior change techniques, is a prerequisite to be able to consistently describe behavioral interventions. The classification of behavior change techniques as taxonomies are typically developed through expert consensus methods. The development of taxonomies of behavior change techniques using the expert consensus method provides an opportunity to develop a formal organized description of techniques that comprise self-determination theory interventions. Development of a formal classification of techniques of self-determination theory interventions will provide the research community with a common set of terms to describe the content of interventions based on the theory, and allow for future empirical testing of which techniques or sets of techniques are most efficacious in promoting motivation and associated outcomes.

\section{The Present Study}

The purpose of the present study was to identify, define, and classify the unique techniques that comprise interventions based on self-determination theory, and develop the first classification of techniques comprising self-determination theory interventions in health behavior contexts. We used an iterative expert-consensus method to develop the classification, 
consistent with methods used to develop taxonomies of behavior change techniques (Kok et al., 2016; Michie, Ashford, et al., 2011; Michie, Hyder, Walia, \& West, 2011; Michie et al., 2013; Michie et al., 2015). Unlike existing behavior change technique taxonomies, we organized the current classification system according to links between the techniques and the psychological constructs stipulated in the process model based on self-determination theory (see Figure 1; Ryan et al., 2008). Specifically, we hypothesized intervention techniques to exert their effects on behavior and associated outcomes through changes in psychological need satisfaction, as well as autonomous and controlled forms of motivation, and amotivation. As the focus of the techniques was on change in motivation types defined by self-determination theory, rather than behavior specifically, the identified techniques are referred to as motivation and behavior change techniques (MBCTs). The development of the classification system ${ }^{1}$ should be viewed as a first step in an ongoing, iterative process, progressively informed by empirical investigation of the effects of MBCTs on behavioral outcomes mediated by satisfaction of psychological needs of autonomy, competence, and relatedness.

\section{Method}

The unique MBCTs based on self-determination theory were identified, labelled, defined, and classified using an iterative expert consensus procedure, similar to procedures used to develop taxonomies of behavior change techniques (e.g., Michie, Ashford, et al., 2011; Michie, Hyder, et al., 2011; Michie et al., 2013; Michie et al., 2015). An MBCT was defined as a distinct, observable and replicable component of an intervention, designed to influence a person's behavior directly or indirectly by impacting the person's ${ }^{2}$ perceptions of autonomy, relatedness, and/or competence need satisfaction in relation to a particular behavior or group of

\footnotetext{
${ }^{1}$ We refer to a classification system rather than taxonomy as our proposed list of MBCTs is not expressed as a taxonomic structure, i.e., a hierarchical relationship in which lower level entities have only one type of relationship with a higher-order entity. The current classification is not, therefore, considered a true taxonomy. ${ }^{2}$ The 'person' refers to the individual or group (e.g., a client, patient, intervention participant) that is the target of the intervention.
} 
related behaviors. The definition was based on previous definitions used in taxonomies of behavior change techniques (Michie et al., 2013), and a recent classification of motivational interviewing techniques (Hardcastle, Fortier, Blake, \& Hagger, 2017). Descriptions of motivational interviewing techniques were useful to inform the definition due to the expressed conceptual links between motivational interviewing and self-determination theory-based intervention techniques (Markland, Ryan, Tobin, \& Rollnick, 2005; Vansteenkiste \& Sheldon, 2006). For example, many of the techniques from motivational interviewing, such as supporting autonomy and exploring change expectations, have good congruence with strategies used in autonomy-support interventions focusing on choice and setting self-referenced goals (Hardcastle et al., 2017; Vansteenkiste, Williams, \& Resnicow, 2012).

\section{Participants}

Experts $(\mathrm{N}=18,11$ men, 7 women $)$ participating in the consensus procedure were leading researchers with expertise in designing, conducting, and evaluating self-determination theory-based interventions in the health domain. Participants were identified from the network of self-determination theory researchers (www.selfdeterminationtheory.org) and recruited by email. Fourteen were psychologists, three were physical activity specialists, and one was a physician and health psychologist. Experts were based in the United Kingdom ( $n=5)$, United States $(n=4)$, Australia $(n=3)$, Belgium $(n=2)$, Sweden $(n=2)$, Canada $(n=1)$, and South Korea $(n=1)$. The core study team (PJT, MM, MS, MSH) developed the first list of techniques, and were responsible for the feedback, discussion, and refinement of the MBCTs. Their collective expertise is in social psychology, behavioral science, medicine, preventive medicine, and exercise and nutrition sciences, and all have specific expertise in selfdetermination theory.

\section{Procedure}

A seven-step expert consensus procedure was adopted (Table 2). The procedure began with the development of an exhaustive list of candidate techniques based on the pooled 
knowledge of the lead author group and a content analysis of previous self-determination theory interventions. This was followed by a series of expert consensus exercises aimed at refining descriptions and content of the candidate items, removing redundancy, and establishing links between the techniques and need-satisfaction constructs from selfdetermination theory.

Step 1: Development of the first list of MBCTs. The study team members generated an initial 'long list' of distinct MBCTs used in self-determination theory-based interventions, derived from a content analysis of published interventions, manipulations, and autonomy support training programs (e.g., Chatzisarantis \& Hagger, 2009; Cheon \& Reeve, 2013; Deci et al., 1994; Haerens et al., 2013; McLachlan \& Hagger, 2010; Patrick, Resnicow, Teixeira, \& Williams, 2013; Reeve \& Jang, 2006; Su \& Reeve, 2011; Tessier et al., 2008) ${ }^{3}$. For each potential distinct MBCT, initial labels and definitions were formulated and discussed among the core study team members (PJT, MM, MS, MSH) until majority agreement was achieved. Specifically, as in taxonomies of behavior change techniques (e.g., Michie, Ashford, et al., 2011; Michie, Hyder, et al., 2011; Michie et al., 2013; Michie et al., 2015), definitions of MBCTs were formulated using active verbs (e.g., elicit, prompt, use).

Step 2: Consensus exercise - Round 1. An initial group of experts $(\mathrm{N}=8)$ was asked to provide written feedback on the initial list of MBCTs from Step 1, regarding the clarity and content of each label and definition, as well as critical details any MBCTs would insufficiently capture ${ }^{4}$.

Step 3: Consensus exercise - Round 2. Based on these experts' comments from Round 1 and on further discussion among the core team (PJT, MM, MS, MSH), the initial list of MBCTs was refined. Comments from Round 1 led to the decision to conduct a second round with an additional pool of experts. In addition, the core team added a function to each MBCTs.

\footnotetext{
${ }^{3}$ References of all included studies are available as an online supplement: https://osf.io/ytfbq/ ${ }^{4}$ Guidelines provided to the experts are available as an online supplement: https://osf.io/f42pe/
} 
The function description outlined the purpose of the MBCT thereby specifying how it targets the proposed primary mechanism of action (i.e., the corresponding need from selfdetermination theory). The label, definition, and function descriptions of each MBCT were discussed among the core study team members until majority agreement was achieved.

In this round, a larger group of experts $(\mathrm{N}=18)$, including the eight experts from Round 1, was asked to respond to a maximum of eight questions about each of 24 MBCTs from the refined list through an online questionnaire, using online surveys administered via the Qualtrics ${ }^{\mathrm{TM}}$ software. The task was divided in two parts. In the first part, experts rated the need-sensitivity of each MBCT, that is, the extent to which each MBCT targeted each of the three psychological needs - autonomy, relatedness and competence, starting with the need hypothesized to be most closely related to the MBCT (Questions 1, 2, and 3) ${ }^{5}$. Reponses were provided on a 5 -point scale $(1=$ definitely no and $5=$ definitely yes $)$. Experts also rated the essentiality of each MBCT is to a self-determination theory-based health intervention (Question 4; coded 1 = essential, $2=$ important but not essential, $3=$ not important, and $4=$ uncertain/don't know). In the second part, experts assessed the specificity of each MBCT by assessing its uniqueness in relation to any of the other MBCTs listed (Question 5; coded $1=$ sufficiently unique, 2 = overlapping considerably, and $3=$ uncertain/don't know). If experts responded "overlapping considerably", they were asked to indicate which of the other technique(s) the MBCT overlapped with (Question 6), and what changes could be done to reduce it (Question 7). Finally, all experts were asked if they wanted to make any other comments on each MBCT, such as changing labels, definitions, or function descriptions (Question 8). Responses to this question were optional, and it used an open-ended response format.

\footnotetext{
${ }^{5}$ The reference list of definitions of basic psychological needs and their focus used by the experts is available as an online supplement: https://osf.io/msu97/
} 
Prior to participating in this exercise, experts were informed about the expected task completion time and they could interrupt at any point, preferably after a set of related questions (i.e., an MBCT). They were also asked to familiarize themselves with the full list of MBCTs label, definition, and function description - before starting the task. Follow-up reminders were sent to experts after 10 days, and all responses were submitted within 2 weeks.

To avoid confusion during the consensus exercise, experts were further informed that (1) when rating the MBCT-need link, each link should be considered separately, irrespective of whether other needs are targeted by the same MBCT; (2) each MBCT should be considered on its own, even if the MBCT is rarely used in isolation in self-determination theory-based interventions; (3) when rating the uniqueness of each MBCT, potential interactions between these techniques should not be considered; and (4) presenting each need separately does not imply that the effect of any MBCT on a given need is independent of other needs.

For the specificity, essentiality, and uniqueness questions, frequencies and mode averages of responses were calculated for each MBCT. Each MBCT was marked as requiring further consideration, if at least one-quarter (25\%) of the experts considered: (1) the technique did not target the need theoretically hypothesized to be more closely linked to the MBCT (by responding 'definitely no', 'probably no' or 'uncertain' to Question 1); (2) at least one of the other two needs to be strongly targeted by the MBCT (i.e. by responding 'definitely yes' to Questions 2 or 3); (3) the technique to be unimportant in a self-determination theory-based health intervention (Question 4); and (4) the technique yielded considerable overlap considerably with other MBCTs (Question 5).

Step 4: Discussion and feedback from core team members. Based on the expert feedback in step 3, the core team members refined the list of MBCTs, based on the results Round 2 of the consensus exercise. For MBCTs rated (a) not important in the context of a selfdetermination theory-based intervention (Question 4), or (b) overlapping considerably with other MBCTs (Question 5), by the panel of experts, the team discussed their removal or 
rewording until majority agreement was achieved. All labels, definitions and function descriptions were revised for comprehensiveness based on the experts' suggestions provided in Question 8.

Step 5: Consensus exercise - Round 3. The same group of experts $(\mathrm{N}=18)$ was asked an additional set of questions about the MBCTs that required further consideration from the previous round; they were also asked to conduct a fine-grained review of the MBCT descriptions for clarity. In addition, for any MBCTs added to the list in this round, experts were asked the same set of questions as in Round 2.

For all MBCTs, where a consensus on their specificity was not reached, experts were asked to rate how (Question 1). Experts could select one of five responses: $1=$ Confident that it is largely specific to the [basic psychological need], $2=$ Uncertain/don't know, $3=$ Confident that it is not specific, and $4=$ Confident that it is not specific. It also targets [alternate basic psychological need] to a large extent, $5=$ Confident that it is not specific. It also targets [alternate basic psychological need] and [alternate basic psychological need] to a large extent. Experts selecting option 2 on Question 1 were asked to provide suggestions to rephrase the function description to improve the specificity of the MBCT (Question 2; open-ended question). Experts selecting options 3, 4, or 5 on Question 1 were asked to indicate how the MBCT targeted each of the needs selected (i.e., the proposed function), (Question 3; openended question).

For all MBCTs where a consensus on their uniqueness was not reached, experts were asked how satisfied they were that the MBCT was sufficiently unique in relation to others considered to be overlapping in Round 2, to justify being listed separately (Question 4; coded 1 = sufficiently unique, 2 = overlapping considerably, and $3=$ uncertain/don't know). If participants responded "overlapping considerably", they were asked to describe why they considered the MCBTs to overlap, and suggest changes to the label, definition and/or function description, to reduce overlap (Question 5 open-ended question). 
Finally, experts were presented with a group of four MBCTs (randomly selected), one at a time, and asked to review the label, definition, and function description for clarity of English language, and suggest minor changes where appropriate. This was an optional, openended response format.

As in Round 3, frequencies and mean or mode averages of responses were calculated for each MBCT. Each MBCT was marked as requiring further consideration, if at least onequarter (25\%) of experts considered that it was not specific to the stipulated need, and/or targeted an alternate need, by returning a 2, 3, 4, or 5 response to Question 1 (i.e. confidence that each MBCT is specific to each of the three psychological needs - autonomy, competence, and relatedness), and that it overlapped considerably with one or both of the other MBCTs by returning a 2 response to Question 4 (i.e., the MBCT is sufficiently unique in relation to other MBCTs or considered to be overlapping).

In addition, intraclass correlation coefficients (ICC) were computed in Rounds 2 and 3 to assess inter-rater reliability of experts' specificity, essentiality, and uniqueness ratings.

Step 6: Revision and finalization of the list of MBCTs. Based on the ratings provided in Round 3, and suggestions for improvement, the core study team refined the list of MBCTs, including amendments to the wording of definitions, labels, and function descriptions to make them more distinct from each other, and exclude redundant MBCTs. No further rounds were required.

\section{Step 7: Comparison of MBCTs and Techniques from the Behavior Change}

Techniques Taxonomy (BCTT) v1. The core study team members compared the final list of MBCTs with the BCTTv1 (Michie et al, 2013). The aim was to identify MBCTs that could overlap with the ones presented in the BCTTv1, and in these cases, clarify the uniqueness of the MBCT.

\section{Results}

Initial Classification: Steps 1 and 2 
The initial 'long list' of MBCTs identified by the core study team from the literature review and expert nomination identified 39 candidate techniques organized under the three psychological need satisfaction categories from self-determination theory - autonomy, competence and relatedness ${ }^{6}$. MBCTs considered to be vague, redundant, or overlapping by participating experts in Round 1 of the consensus method were reformulated or removed. The revised list comprised $24 \mathrm{MBCTs}$, eight for each need satisfaction category ${ }^{7}$. The label, definition, and function description of each MBCT was revised for clarity. A definitions key for each psychological need under which the MBCTs were classified was also developed to accompany the list of MBCTs.

\section{Refining the Techniques: Steps 3 and 4}

In Round 2, experts provided responses to each of the three criteria for rating the candidate MBCTs identified in Round 1: specificity, essentiality, and uniqueness ${ }^{8}$. With respect to the specificity criterion, all MBCTs were rated as sufficient in targeting the primary need, with responses ranging from "probably yes" to "definitely yes". There were some instances where MBCTs were identified as targeting needs other than the hypothesized need. Specifically, the "facilitate autonomous goals or outcomes" (autonomy) and "support client's initiatives and explorations around behavior change" (autonomy) MBCTs were rated as “definitely yes" as also targeting competence by $38.9 \%$ and $44.4 \%$ of experts, respectively. In addition, the "acknowledge and accept client's perspectives" (relatedness) and "encourage client to ask questions" (relatedness) MBCTs were both rated "definitely yes" as also targeting autonomy by half of the experts. The "ask permission to provide information or give advice" (relatedness) MBCT was rated "definitely yes" as also targeting autonomy by $38.9 \%$ of

\footnotetext{
${ }^{6}$ The list of MBCTs for all rounds are presented as an online supplement: https://osf.io/2vh8y ${ }^{7}$ Changes are documented in an online supplement: https://osf.io/2vh8y

${ }^{8} \mathrm{~A}$ summary table of experts' ratings of the MBCTs in Round 2 of the consensus survey is provided as an online supplement (https://osf.io/fu38t/), along with a table providing full results for each MBCT (https://osf.io/cf3n7/).
} 
experts. In addition, a substantive proportion of experts (33.3\%) considered the MBCT "explore sources of support from others" (competence) to also target relatedness.

With respect to essentiality, all MBCTs were considered essential or important techniques for self-determination theory-based interventions. A substantive minority $(27.8 \%)$ of experts expressed uncertainty over the importance of the "explore means to manage and cope with pressure" (competence) MBCT.

In terms of uniqueness ratings, only six of the MBCTs were judged to be conceptually unique and free of considerable overlap with other MBCTs ${ }^{9}$. From experts' comments and suggestions to reduce overlap, it became clear that, when answering this question, some experts were considering the interactions that occur between MBCTs in a given intervention, rather than their potential conceptual overlap (e.g., the "acknowledge and accept the client's perspectives" and "acknowledge feelings" MBCTs were rated as overlapping by $55.6 \%$ of experts). In Round 3, instructions for this section were improved.

The ICC values showed good consensus on ratings of specificity $(\mathrm{ICC}=.929,95 \% \mathrm{CI}$ $[.873, .968])$, essentiality $(\mathrm{ICC}=.784,95 \% \mathrm{CI}[.623, .902])$, and uniqueness $(\mathrm{ICC}=.902,95 \%$ CI $[.823, .957])$.

Based on these ratings, one MBCT was removed ('Support client's initiatives and explorations around behavior change"), and two further MBCTs were added under the autonomy need satisfaction category: "explore intrinsic rewards" and "encourage the person to be supportive towards others with a similar condition". Changes were also made to the wording of the labels, definitions, and function descriptions of the MBCTs. The refined classification comprised 25 MBCTs, classified under the autonomy $(\mathrm{n}=9)$, relatedness $(\mathrm{n}=8)$, and competence $(n=8)$ need satisfaction categories, respectively ${ }^{10}$.

\section{Finalizing the Classification: Steps 5 and 6}

\footnotetext{
${ }^{9}$ Full details of overlapping MBCTs are provided in an online supplement: https://osf.io/cf3n7/

${ }^{10} \mathrm{~A}$ full description of changes made to the MBCTs is provided in an online supplement: https://osf.io/2vh8y/
} 
In Round 3 of the expert consensus procedure, experts $(n=16)$ were asked to rate the two additional MBCTs using the same procedure as in Round $2^{11}$. With respect to the uniqueness criterion, the majority of the experts $(68.8 \%)$ judged the "encourage the person to be supportive towards others with a similar condition" MBCT to be more relevant to competence and relatedness needs rather than its original classification under the autonomy need. Both new MBCTs were judged to be conceptually unique and not overlapping with all the other MBCTs, except for the overlap between the "explore intrinsic rewards" and “facilitate autonomous goals or outcomes" MBCTs (43.8\% of experts).

In terms of specificity judgements, the "acknowledge and respect perspectives" (relatedness), “ask permission to provide information or give advice” (relatedness), and “explore sources of support from others" (competence) MBCTs, were again judged by a substantive proportion of the experts $(56.3 \%, 31.3 \%$, and $43.7 \%$, respectively) as targeting autonomy and relatedness.

Focusing on the uniqueness ratings, most MBCTs from the previous round were still judged by experts as overlapping with other MBCTs. However, the number of MBCTs with which each MBCT was judged to overlap decreased. For example, the "explore life aspirations and values" MBCT was considered to overlap with four other MBCTs in Round 2, while in the current round it was judged by a majority $(56.3 \%)$ of experts to overlap with the "facilitate autonomous goals or outcomes" MBCT alone. In addition, the "show unconditional regard" and "take interest the person" MBCTs were rated conceptually unique.

The ICC scores showed good consensus on ratings of specificity (ICC $=.658,95 \% \mathrm{CI}$ $[.334, .859])$, and uniqueness $(\mathrm{ICC}=.955,95 \% \mathrm{CI}[.917, .981])$.

Based on the ratings and suggestions from experts on the wording of the MBCTs, the core study team revised the list of MBCTs. For the autonomy need category, the new

\footnotetext{
${ }^{11}$ Full results of the consensus procedure for Round 3 are provided in an online supplement: https://osf.io/amnr4/
} 
"encourage the person to be supportive towards others with a similar condition" MBCT and the "facilitate autonomous goals or outcomes" MBCT were consolidated into the "provide choice" MBCT. The "acknowledge and respect perspectives" and "acknowledge feelings" MBCTs were consolidated, and the "ask permission to provide information or give advice" MBCT was removed and integrated with the "use empathic listening" MBCT. In addition, the "explore sources of support from others" MBCT was reclassified from the competence need category to the relatedness category. In addition, the wording of labels, definitions, and function descriptions of the MBCTs was also revised based on experts'suggestions. The final classification of MBCTs $(\mathrm{N}=21)$ with formal agreed labels, definitions, function descriptions, and categorization according to their primary psychological need is presented in Table $3^{12}$.

\section{Commonalities with Other Taxonomies: Step 7}

The core study team matched the final list of MBCTs produced after the Round 3 consensus procedure with key BCTs from BCTTv $1^{13}$. Seven MBCTs were considered overlapping with existing BCTs, five of which were techniques hypothesized to improve competence ${ }^{13}$. However, it is important to note that the definitions and function descriptions of the MBCTs set these techniques aside from the matched BCTTv1. This is because each MBCT is aligned with a theoretical construct from self-determination theory integral to the mechanism by which it is purported to change motivation and behavior. Specifically, each MBCT is defined in terms of the psychological need expected to mediate its effect on behavior change. Whilst BCTTv1 has been linked using consensus and literature reviewing methods to theoretical constructs (Carey et al., 2019; Connell et al., 2018), there has been no taxonomy or classification linking MBCTs to the key constructs of self-determination theory. In addition,

\footnotetext{
${ }^{12}$ Illustrative examples of each MBCT for client-practitioner interactions are provided in an online supplement: https://osf.io/mhw5x/

${ }^{13}$ Full results of the matching exercise are provided in an online supplement: https://osf.io/8jtm3/
} 
the MBCTs are proposed to evoke change in motivation as well as behavior as end-points, while techniques from BCTTv1 are exclusively defined in terms of changing behavior.

\section{Discussion}

The current research aimed to identify, describe, and classify the techniques employed in motivation and behavior change interventions based on self-determination theory in health contexts. The research extends knowledge on behavioral interventions based on the theory in the health domain by providing a common set of terms and definitions for the identified techniques. This classification is organized by the links between techniques and the psychological need satisfaction constructs implicated in the mechanism by which the techniques change motivation and behavior in accordance with Ryan et al.'s (2008) process model (Figure 1). Consistent with the focus of self-determination theory on motivation quality, techniques aimed at the end-points of motivation and behavior were labelled motivation and behavior change techniques (MBCTs). We used an iterative expert consensus procedure to identify, define, and classify techniques used in self-determination theory-based interventions, similar to the procedures used to develop taxonomies of behavior change techniques (Michie et al., 2005; Michie et al., 2013; Michie et al., 2015). This procedure yielded 21 MBCTs with accompanying labels, definitions, and function descriptions, and each MBCT was classified into autonomy, competence, and relatedness need satisfaction categories.

\section{Interrelatedness Among Techniques and Relations to 'Motivating Styles'}

While the expert panel and iterative procedure used in the current analysis led to general consensus on the techniques that comprise self-determination theory-based interventions, and that each technique principally targeted change in one of the three basic psychological needs, the experts also suggested that many of the techniques targeted change in other needs. This is consistent with the premises of self-determination theory. Although clear conceptual distinctions are proposed among the basic needs, the theory also states that the needs are complimentary. According to Ryan and Deci (2017), "the three basic needs are 
interdependent" because "the satisfaction of one need supports the satisfaction of the other two needs" (p. 249). In addition, at the empirical level, measures of the three needs routinely intercorrelate and factor analyses reveal that measures of satisfaction of the three psychological needs form a higher order need satisfaction factor (Hagger, Chatzisarantis, \& Harris, 2006).

That the MBCTs identified in the current research had close affinity to one need, but were also linked to satisfaction of one or both of the other needs, is consistent with this premise. Furthermore, although there is evidence to suggest that individual techniques can alone be efficacious in changing motivation and outcomes (e.g., provision of choice, Patall, Cooper, \& Robinson, 2008), many techniques are designed to be used interactively. For instance, an intervention providing a rationale for engaging in a task or behavior (MBCT5) is not likely to promote autonomy satisfaction by itself, but a rationale paired with perspective taking (MBCT1) and acknowledgement of negative feelings (MBCT8) is more likely to promote autonomy satisfaction, and engagement (e.g., Deci et al., 1994; Jang et al., 2010; Reeve, Jang, Hardre, \& Omura, 2002). Similar effects have been found in the setting of intrinsic goals (Vansteenkiste, Simons, Lens, \& Sheldon, 2004; Vansteenkiste, Simons, Soenens, \& Lens, 2004). Taken together, these theoretical perspectives and research suggest considerable interrelatedness among the MBCTs and the underlying constructs they are proposed to change.

MBCT interrelatedness is consistent to the notion that promoting motivation change using self-determination theory interventions involves adoption of 'motivating styles' by social agents. Such 'agents' operate in multiple contexts such as healthcare (Williams \& Deci, 1996), education (Reeve \& Jang, 2006), the workplace (Gagné \& Deci, 2005), sport and coaching (Carpentier \& Mageau, 2016), parenting (Joussemet, Landry, \& Koestner, 2008), and therapy (Zuroff et al., 2007), and are responsible for supporting and nurturing autonomy among their supervisees including patients, students, employees, athletes, and clients. The motivating styles adopted by social agents frequently involve the simultaneous display of multiple MBCTs that act synergistically in promoting need support and motivation change. Research has sought to 
identify and describe motivating styles of social agents (Aelterman et al., 2019; Aelterman et al., 2014; Delrue et al., 2019). A recent approach has been to characterize motivating styles in a circumplex structure, with identified motivating styles differing in terms of their needsupportive vs. need-thwarting character and their level of directiveness, with either the motivating agent taking more the lead in the interaction or the person to be motivated being more in charge (Aelterman et al., 2019). Within this circumplex, four broader motivating styles get partitioned into two distinct approaches, that is, participative and attuning (i.e., autonomy support), guiding and clarifying (i.e., structure), demanding and domineering (i.e., control), abandoning and awaiting (i.e., chaos). These eight subareas display an ordered pattern with individuals' motivation and need satisfaction (Aelterman et al., 2019; Delrue et al., 2019), with the most pronounced positive correlates being observed for the most need-nurturing approaches (i.e., guiding, attuning) and the most negative correlates being observed for the most need-thwarting approaches (i.e., domineering, abandoning). Interestingly, the other identified subareas fall in between these two extremes, suggesting that some motivating techniques are more strongly conducive to need satisfaction than others. This pattern of gradations may also surface for the identified techniques herein, with some techniques being more strongly conducive to the psychological needs and others instead creating the optimal conditions for need satisfying experiences for clients to emerge.

The interrelatedness among the MBCTs and the adoption of a motivating styles approach seems, at first glance, to be at loggerheads with the notion of identifying separate, unique MBCTs. A primary function of taxonomies of behavior change techniques is to develop a common set of descriptions and definitions of the unique techniques that comprise behavioral interventions. A further goal of taxonomies is to provide researchers with means to develop studies that isolate the unique and interactive effects of individual intervention techniques on behavior change using factorial designs. This is aimed at developing optimally effective and efficient interventions that work in given contexts, populations, and behaviors. Applying this 
approach to produce the current classification of MBCTs serves a similar function, and allows researchers to develop tests to establish the unique and interactive effects of the different techniques of self-determination theory interventions in evoking change in need satisfaction, motivation, and behavior. However, such a 'micro' approach to self-determination theorybased interventions does not need to be irreconcilable with the more 'macro' approach epitomized by motivating styles. In fact, they may be complimentary by using the classification to describe specific groups of behaviors expected to be displayed in each motivating style. Potentially, each style could be characterized by groups of MBCTs derived from the current classification in a 'profile' approach, and this may be a direction for future research.

\section{Mechanisms of Effect}

A unique feature of the current classification of MBCTs is that it specifies explicit links between the MBCTs and the psychological need satisfaction constructs from selfdetermination theory. Organizing behavior change techniques according to the theoretical constructs they are purported to change provides important information on how interventions are likely to 'work' in changing behavior (Carey et al., 2019; Connell et al., 2018). The current organization of MBCTs may inform efforts to identify possible mediators of intervention effects, and, therefore, the mechanisms by which self-determination theory interventions promote motivation change and affect outcomes (Hagger et al., 2020; Sheeran et al., 2017). Consistent with the process model presented in Figure 1 (Ryan et al., 2008), employing the MCBTs from the current classification in behavior interventions is expected to affect change in the satisfaction of their respective psychological need. Specifically, autonomy-supportive MBCTs are proposed to support autonomy need satisfaction in that they facilitate individuals' sense of self-endorsed satisfaction, volition, sense of choice, ownership, and personal endorsement of the task or behavior. Competence-supportive MBCTs are expected to support competence need satisfaction through facilitation of individuals' sense of satisfaction in making progress, improvement, attaining mastery, and greater skill development on mental and 
physical tasks and behaviors. Relatedness-supportive MBCTs are predicted to foster relatedness need satisfaction by engendering individuals' sense of interpersonal connectedness, closeness, acceptance, understanding, intimacy, and unconditional regard. The links between the MBCTs and specific need satisfaction constructs highlight the imperative of including measures of the relevant need satisfaction constructs in research evaluating effects of MBCTbased interventions to test the proposed mechanisms.

\section{Links with Other Classifications of Techniques}

We also compared the set of MBCTs identified in current classification with those from BCTTv1 (Michie et al., 2013), a procedure which has been conducted for other classifications of behavior change techniques (Hardcastle et al., 2017). The goal of the comparison was to identify commonalities and redundancies across techniques and illustrate the distinctiveness of the self-determination theory-based techniques identified in the current classification. Results of the comparison illustrated that many of the MBCTs (five out of seven) classified under competence need satisfaction shared similar content to those of existing taxonomies, particularly the BCTTv1 (Michie et al., 2013). The congruent techniques are likely those aimed at promoting change through changes in constructs such as self-efficacy, confidence, and control. However, comparisons across the techniques from existing taxonomies should also be interpreted in light of the explicit alignment of the MBCTs with self-determination theory, and the focus on both motivation and behavior change. While recent work has specified links between 56 behavior change techniques and 26 mechanisms of action (Carey et al., 2019; Connell et al., 2018; Michie et al., 2015), these were not theory-specific. Although there were techniques identified as having close content across the taxonomies in our comparison, we opted to retain the MBCTs in the current classification because they have explicitly been linked to the need satisfaction constructs from self-determination theory, and have a different focus to those specified in existing taxonomies. 
The current research advances knowledge by identifying the sets of techniques that comprise self-determination theory-based interventions, providing a common set of labels and descriptions for the techniques, and producing a classification system of the techniques with basic psychological needs as an organizing principle. A major strength of the research is the adoption of a rigorous expert-consensus procedure in order to arrive at agreed definitions, descriptions, and classifications of self-determination theory intervention content. The panel of experts comprised career researchers with considerable experience in applying selfdetermination theory interventions across multiple behaviors, populations, and contexts, and had in-depth knowledge of the extant research literature on self-determination theory interventions. The panel applied this pooled knowledge in their evaluation of the candidate set of techniques during the consensus rounds. The panel did not flag any omissions from the set, lending support for its comprehensiveness. The procedure provided strong quality control over the finalized terminology and descriptions of the techniques. Therefore, we are confident our strategy was sufficiently comprehensive in identifying relevant techniques from the extant literature, and developing common terms and descriptions of MBCTs that can be adopted by future researchers to describe the content of self-determination theory-based interventions.

The present research also represents a step forward in specifying the content of selfdetermination theory-based intervention in health behavior contexts. A key feature of our classification system is the development of standardized labels, definitions, and function descriptions for each MBCT. We encourage future researchers and interventionists to apply the common terminology developed in the current classification when describing the content of interventions based on self-determination theory. This will minimize variability and increase precision in future descriptions of intervention content, and facilitate comparisons in content across interventions based on self-determination theory, a key goal of classification systems (Michie, Ashford, et al., 2011; Michie, Hyder, et al., 2011; Michie et al., 2013; Michie et al., 2015). 
In addition, we expect the increased capacity to directly compare intervention content afforded by the classification will improve syntheses of evidence across self-determination theory-based interventions, which have been somewhat hindered by a lack of consensus in means to describe and characterize essential techniques that comprise these interventions (Michie \& Abraham, 2008; Ryan et al., 2008). The lack of consensus in descriptions creates considerable problems for researchers attempting to synthesize findings across studies because it makes it difficult to establish equivalence of intervention content across studies and, therefore, evaluate intervention efficacy. The current classification is an essential pre-requisite to the future development of coding systems that enable researchers to effectively link the descriptions of self-determination theory interventions extracted from studies with the MBCTs from the current classification (see Cane, Richardson, Johnston, Ladha, \& Michie, 2015 for examples; Michie et al., 2015). Together, such work will permit evaluation of the efficacy of MBCTs in changing behavior through meta-analytic syntheses of intervention studies based on self-determination theory. Such syntheses can assist in establishing whether the presence or absence of specific MBCTs from the classification are efficacious in changing behavior. That, in itself, is challenging given that few studies adopt factorial designs testing effects of individual techniques, so such analyses are always going to be hampered by the presence of other potentially confounding, co-occurring, or interacting techniques (Peters, de Bruin, \& Crutzen, 2015). Nevertheless, the current analysis is expected to pave the way for future syntheses evaluating effects of individual, isolated intervention techniques based on selfdetermination theory on behavior change, or the effects of particular combinations of techniques. These syntheses contribute to the development of a database of information that researchers can draw from when developing behavior change intervention based on selfdetermination theory.

Related to the previous point, we expect the classification will help researchers develop interventions testing the efficacy of particular techniques or groups of techniques in changing 
motivation and behavior. We expect it will inform the development of studies using factorial designs to test the unique and, importantly, interactive effects of groups of techniques on motivational and behavioral outcomes. Such research may, ultimately, facilitate research syntheses on the efficacy of individual technique in changing motivation and behavior of the kind alluded to earlier. It will also inform the development of more efficient interventions through the selection of techniques shown to be effective, and the elimination of those shown to be ineffective, in changing motivation and behavior.

Our current research was developed in the domain of health behavior, a decision based on the extensive research applying self-determination theory in this domain, and the importance of behavior change and its maintenance to the prevention of chronic disease. However, the classification system could be applied to behavior change interventions in different domains, such as education and the workplace. Further research is needed to examine the cross-domain generalizability of the MBCTs identified in the current classification. Further, the expert consensus procedures adopted in the current research may also have implications for the development of similar classifications of techniques for other theories in the motivation and social psychological literature, and our approach based on theory, evidence, and expert consensus may provide a template for doing so.

\section{Limitations}

Some limitations of the current research should be acknowledged. Although experts were generally supportive of the use of psychological needs as a general organizing principle, and that each MBCTs is classified under its 'primary' or most closely matched psychological need but may also be related to other needs, no hierarchy is offered. In fact, for some MBCTs there was debate among experts as to which of the need satisfaction constructs was the closest match. While we report the ancillary need satisfaction constructs linked to the techniques in the course of the consensus procedure, the current classification does not provide an elaborated 
'map' of relations between the techniques and the needs they are likely to satisfy, and this should be a goal of future research.

A further caveat is that although the links between psychological needs and the MBCTs were derived through a rigorous expert-consensus procedure, they are not based on empirical evidence from health behavior change interventions. So, the classification does not reflect the quality or strength of evidence for the links that have been tested. Instead, the links specified in the current classification should be viewed as guidance on the potential mediators of the effects of MBCTs on motivation and behavior. The classification should, therefore, inform future research that synthesizes evidence on the mechanisms by which self-determination theorybased interventions change behavior, as well inform the design of studies to test proposed relations for which no previous evidence exists or is lacking. In such cases, the links expressed in the current classification should be treated as theoretical predictions subject to confirmation or rejection through empirical tests (Hagger, Gucciardi, \& Chatzisarantis, 2017). Such research will move knowledge and understanding of which techniques work in changing motivation and behavior in health contexts forward, and assist in identifying the mechanisms responsible. To speculate, it may be that some individual or groups of MBCTs have larger effects on motivational and behavioral outcomes than others, and over time cumulative empirical evidence may assist in identifying a 'core' set of self-determination theory techniques that are most reliably efficacious in changing motivation and behavior.

A related issue of note is that our classification of MBCTs is silent on the effects of the techniques themselves on outcomes including motivation and behavior. In fact, this is a feature of all taxonomies of behavior change techniques (e.g., Michie, Ashford, et al., 2011; Michie et al., 2013). This is because the goal was to develop a means to describe and classify the content of behavior change interventions based on self-determination theory, rather than providing an evaluation of whether each technique is efficacious in determining change. In fact, such an endeavor is difficult for the very reason the current classification was developed in the first 
place - it is difficult to evaluate effects of techniques across studies because studies have tended not to intervention content with sufficient precision, vary in the terms and language used, and also differ in the number and combination of techniques used. As the field moves toward more elaborated ontologies of behavior change (Larsen et al., 2016; Michie \& Johnston, 2017), the content of the current classification may be merged with syntheses of research demonstrating MBCT efficacy and further links between MBCTs and constructs representing mechanisms of effect. Such ontologies will provide intervention designers with the comprehensive theory- and evidence-based knowledge necessary to develop interventions that have optimal efficacy, and the current classification is an important step forward in their development.

In addition, research is needed to determine whether specific MBCTs identified in the current classification interact with conditions that moderate their efficacy in change and maintenance of motivation, health behaviors, well-being, and disease burden. Such conditions may include, but are not limited to, contact time between the practitioner or social agent and the client or patient, frequency of contact, duration of intervention, type and training of social agents (e.g., peer, family member, co-worker, teacher, clinician, or public health scientist), and intervention cost. Once efficacy of interventions adopting individual or groups of MBCTs has been established, they need to be tested for efficacy and effectiveness, cost-effectiveness, implementation, and dissemination. In addition, the experts that contributed to the current classification comprise largely of psychologists and behavioral scientists. Input is needed from other stakeholders and practitioners (e.g., health professionals, teachers, public health scientists, medical ethicists, peers, family members) who may assist in refining the content of the current techniques, or may identify additional techniques that may satisfy psychological needs and promote health behaviors that are currently not included in this classification.

Finally, recent research on self-determination theory has made the distinction between need-supporting and need-thwarting strategies in evoking change in different types of 
motivation and behavioral engagement (e.g., Bartholomew et al., 2011; Haerens et al., 2015; Hein, Koka, \& Hagger, 2015; Vansteenkiste \& Ryan, 2013). While the lack of satisfaction of psychological needs has been linked with reduced propensity to engage in behaviors for autonomous reasons and reduced likelihood of attaining adaptive outcomes, including behavioral persistence (Deci \& Ryan, 2000; Deci, Spiegel, Ryan, Koestner, \& Kauffman, 1982; Koestner, Ryan, Bernieri, \& Holt, 1984), recent research has identified the deleterious effects of thwarting or frustration of psychological needs on outcomes including behavioral avoidance or disengagement (Bartholomew et al., 2011; Ryan \& Deci, 2017; Vansteenkiste \& Ryan, 2013). In fact, recent theory has proposed a 'dual process' framework, proposing that motivation is a function of need supportive and need thwarting processes that act in parallel (Jang, Kim, \& Reeve, 2016). Just as the need-supportive techniques identified in the current classification enhance autonomous motivation, need thwarting strategies, such as controlling interpersonal styles (e.g., use of contingent rewards), undermine autonomous motivation and engender controlled motivation. Although avoidance of controlling techniques is referred to within the current classification (e.g., "Use non-controlling, informational language", MBCT 3), there has been no formal inclusion of techniques that thwart psychological needs. Future research should seek to augment the current classification to encompass need-thwarting techniques so that their effect can be also further explored and tested.

\section{Conclusion}

The present study developed an organized classification of the unique motivation and behavior-change techniques (MBCTs) used in self-determination theory interventions to change motivation toward, and participation in, health behavior. Our theory-based, expert consensus procedure found support for $21 \mathrm{MBCT}$ s organized according to the primary psychological need (autonomy, competence, or relatedness) they are purported to change. A key goal of the current classification is to provide researchers and interventionists with a common set of terms and definitions to describe the content of self-determination theory-based 
interventions in health contexts, and we expect it to facilitate the precision of descriptions of future self-determination interventions. As with taxonomies of behavior change techniques, the current classification is designed to be a first step in specifying the content of self-

determination theory-based interventions in health behavior contexts. The classification should therefore be viewed as one that is flexible and open to modification as new evidence is made available. Future research should aim to use the classification to inform the development of self-determination theory-based interventions that test the efficacy of specific techniques in changing health behavior. The classification system may also inform future coding of research aimed at synthesizing evidence for self-determination theory-based interventions. Finally, although the current classification is focused on health contexts, it may have broader implications in other contexts. For example, the classification may form the basis of research aimed at classifying and describing techniques used in self-determination theory-based interventions in educational, organizational, and environmental contexts. 


\section{References}

Aelterman, N., Vansteenkiste, M., Haerens, L., Soenens, B., Fontaine, J. R. J., \& Reeve, J. (2019). Toward an integrative and fine-grained insight in motivating and demotivating teaching styles: The merits of a circumplex approach. Journal of Educational Psychology, 11, 497-521. http://dx.doi.org/10.1037/edu0000293

Aelterman, N., Vansteenkiste, M., Van den Berghe, L., De Meyer, J., \& Haerens, L. (2014). Fostering a need-supportive teaching style: Intervention effects on physical education teachers' beliefs and teaching behaviors. Journal of Sport and Exercise Psychology, 36, 595-609. http://dx.doi.org/10.1123/jsep.2013-0229

Bartholomew, K. J., Ntoumanis, N., Ryan, R. M., Bosch, J. A., \& Thogersen-Ntoumani, C. (2011). Self-determination theory and diminished functioning: The role of interpersonal control and psychological need thwarting. Personality and Social Psychology Bulletin, 37, 1459-1473. http://dx.doi.org/10.1177/0146167211413125

Bartholomew, L. K., \& Mullen, P. D. (2011). Five roles for using theory and evidence in the design and testing of behavior change interventions. Journal of Public Health Dentistry, 71, S20-S33. http://dx.doi.org/10.1111/j.1752-7325.2011.00223.x

Cane, J., Richardson, M., Johnston, M., Ladha, R., \& Michie, S. (2015). From lists of behaviour change techniques (BCTs) to structured hierarchies: Comparison of two methods of developing a hierarchy of BCTs. British Journal of Health Psychology, 20, 130-150. http://dx.doi.org/10.1111/bjhp.12102

Carey, R. N., Connell, L. E., Johnston, M., Rothman, A. J., de Bruin, M., Kelly, M. P., \& Michie, S. (2019). Behavior change techniques and their mechanisms of action: A synthesis of links described in published intervention literature. Annals of Behavioral Medicine, 53, 693-707. http://dx.doi.org/10.1093/abm/kay078

Carpentier, J., \& Mageau, G. A. (2016). Predicting sport experience during training: The role of change-oriented feedback in athletes' motivation, self-confidence and needs 
satisfaction fluctuations. Journal of Sport \& Exercise Psychology, 38, 45. http://dx.doi.org/10.1123/jsep.2015-0210

Chatzisarantis, N. L. D., \& Hagger, M. S. (2009). Effects of an intervention based on selfdetermination theory on self-reported leisure-time physical activity participation. Psychology and Health, 24, 29-48. http://dx.doi.org/10.1080/08870440701809533

Chen, B., Vansteenkiste, M., Beyers, W., Boone, L., Deci, E. L., Van der Kaap-Deeder, J., . . . Verstuyf, J. (2015). Basic psychological need satisfaction, need frustration, and need strength across four cultures. Motivation and Emotion, 39, 216-236. http://dx.doi.org/10.1007/s11031-014-9450-1

Cheon, S. H., \& Reeve, J. (2013). Do the benefits from autonomy-supportive PE teacher training programs endure?: A one-year follow-up investigation. Psychology of Sport and Exercise, 14, 508-518. http://dx.doi.org/10.1016/j.psychsport.2013.02.002

Cheon, S. H., Reeve, J., \& Moon, I. (2012). Experimentally based, longitudinally designed, teacher-focused intervention to help physical education teachers be more autonomy supportive toward their students. Journal of Sport and Exercise Psychology, 34, 365396. http://dx.doi.org/10.1123/jsep.34.3.365

Cheon, S. H., Reeve, J., \& Ntoumanis, N. (2018). A needs-supportive intervention to help PE teachers enhance students' prosocial behavior and diminish antisocial behavior. Psychology of Sport and Exercise, 35, 74-88. http://dx.doi.org/10.1016/j.psychsport.2017.11.010

Connell, L. E., Carey, R. N., de Bruin, M., Rothman, A. J., Johnston, M., Kelly, M. P., \& Michie, S. (2018). Links between behavior change techniques and mechanisms of action: An expert consensus study. Annals of Behavioral Medicine, 53, 708-720. http://dx.doi.org/10.1093/abm/kay082 
Deci, E. L., Eghrari, H., Patrick, B. C., \& Leone, D. R. (1994). Facilitating internalization: The self-determination theory perspective. Journal of Personality, 62, 119-142. http://dx.doi.org/10.1111/j.1467-6494.1994.tb00797.x

Deci, E. L., \& Ryan, R. M. (1985). Intrinsic motivation and self-determination in human behavior. New York, NY: Plenum Press.

Deci, E. L., \& Ryan, R. M. (2000). The "what" and "why" of goal pursuits: Human needs and the self-determination of behavior. Psychological Inquiry, 11, 227-268. http://dx.doi.org/10.1207/S15327965PLI1104_01

Deci, E. L., Spiegel, N. H., Ryan, R. M., Koestner, R., \& Kauffman, M. (1982). Effects of performance standards on teaching styles: Behavior of controlling teachers. Journal of Educational Psychology, 74, 852-859. http://dx.doi.org/10.1037/0022-0663.74.6.852

Delrue, J., Reynders, B., Broek, G. V., Aelterman, N., De Backer, M., Decroos, S., . . . Vansteenkiste, M. (2019). Adopting a helicopter-perspective towards motivating and demotivating coaching: A circumplex approach. Psychology of Sport and Exercise, 40, 110-126. http://dx.doi.org/10.1016/i.psychsport.2018.08.008

Duda, J. L., Williams, G. W., Ntoumanis, N., Daley, A., Eves, F. F., Mutrie, N., . . Jolly, K. (2014). Effects of a standard provision versus an autonomy supportive exercise referral programme on physical activity, quality of life and well-being indicators: a cluster randomised controlled trial. International Journal of Behavioral Nutrition and Physical Activity, 11, 10. http://dx.doi.org/10.1186/1479-5868-11-10

Dunton, G. F., Cousineau, M., \& Reynolds, K. D. (2010). The intersecton of public policy and health behavior in the physical activity arena. Journal of Physical Activity \& Health, 7 , S91-S98. http://dx.doi.org/10.1123/jpah.7.s1.s91

Emm-Collison, L. G., Jago, R., Salway, R., Thompson, J. L., \& Sebire, S. J. (2019). Longitudinal associations between parents' motivations to exercise and their moderate- 
to-vigorous physical activity. Psychology of Sport and Exercise, 43, 343-349.

http://dx.doi.org/10.1016/j.psychsport.2019.04.007

Froiland, J. M. (2015). Parents' weekly descriptions of autonomy supportive communication: Promoting children's motivation to learn and positive emotions. Journal of Child and Family Studies, 24, 117-126. http://dx.doi.org/10.1007/s10826-013-9819-x

Gagné, M., \& Deci, E. L. (2005). Self-determination theory and work motivation. Journal of Organizational Behavior, 26, 331-362. http://dx.doi.org/10.1002/job.322

Gillison, F. B., Rouse, P., Standage, M., Sebire, S., \& Ryan, R. M. (2018). A meta-analysis of techniques to promote motivation for health behaviour change from a selfdetermination theory perspective. Health Psychology Review, 13, 110-130. http://dx.doi.org/10.1080/17437199.2018.1534071

Glanz, K., \& Bishop, D. B. (2010). The role of behavioral science theory in development and implementation of public health interventions. Annual Review of Public Health, 31, 399-418. http://dx.doi.org/10.1146/annurev.publhealth.012809.103604

Haerens, L., Aelterman, N., van den Berghe, L., de Meyer, J., Soenens, B., \& Vansteenkiste, M. (2013). Observing physical education teachers' need-supportive interactions in classroom settings. Journal of Sport \& Exercise Psychology, 35, 3-17. http://dx.doi.org/10.1123/jsep.35.1.3

Haerens, L., Aelterman, N., Vansteenkiste, M., Soenens, B., \& Van Petegem, S. (2015). Do perceived autonomy-supportive and controlling teaching relate to physical education students' motivational experiences through unique pathways? Distinguishing between the bright and dark side of motivation. Psychology of Sport and Exercise, 16, 26-36. http://dx.doi.org/10.1016/j.psychsport.2014.08.013

Hagger, M. S., Cameron, L. D., Hamilton, K., Hankonen, N., \& Lintunen, T. (2020). Changing behavior: A theory- and evidence-based approach. In M. S. Hagger, L. D. Cameron, K. 
Hamilton, N. Hankonen \& T. Lintunen (Eds.), The Handbook of Behavior Change. New York, NY: Cambridge University Press.

Hagger, M. S., \& Chatzisarantis, N. L. D. (2015). Self-determination theory. In M. T. Conner \& P. Norman (Eds.), Predicting and changing health behaviour: Research and practice with social cognition models (3rd ed., pp. 107-141). Maidenhead, UK: Open University Press.

Hagger, M. S., Chatzisarantis, N. L. D., \& Harris, J. (2006). From psychological need satisfaction to intentional behavior: Testing a motivational sequence in two behavioral contexts. Personality and Social Psychology Bulletin, 32, 131-138. http://dx.doi.org/10.1177/0146167205279905

Hagger, M. S., Gucciardi, D. F., \& Chatzisarantis, N. L. D. (2017). On nomological validity and auxiliary assumptions: The importance of simultaneously testing effects in social cognitive theories applied to health behavior and some guidelines. Frontiers in Psychology, 8, 1933. http://dx.doi.org/10.3389/fpsyg.2017.01933

Halvari, A. E. M., \& Halvari, H. (2006). Motivational predictors of change in oral health: An experimental test of self-determination theory. Motivation and Emotion, 30, 294. http://dx.doi.org/10.1007/s11031-006-9035-8

Hardcastle, S. J., Fortier, M. S., Blake, N., \& Hagger, M. S. (2017). Identifying content-based and relational techniques to change behavior in motivational interviewing. Health Psychology Review, 11, 1-16. http://dx.doi.org/10.1080/17437199.2016.1190659

Hein, V., Koka, A., \& Hagger, M. S. (2015). Relationships between perceived teachers' controlling behaviour, psychological need thwarting, anger and bullying behaviour in high-school students. Journal of Adolescence, 42, 103-114.

http://dx.doi.org/10.1016/j.adolescence.2015.04.003

Jang, H., Kim, E. J., \& Reeve, J. (2016). Why students become more engaged or more disengaged during the semester: A self-determination theory dual-process model. 
Learning and Instruction, 43, 27-38.

http://dx.doi.org/10.1016/j.learninstruc.2016.01.002

Jang, H., Reeve, J., \& Deci, E. L. (2010). Engaging students in learning activities: It is not autonomy support or structure but autonomy support and structure. Journal of Educational Psychology, 102, 588-600. http://dx.doi.org/10.1037/a0019682

Johnson, B. T., \& Acabchuk, R. L. (2018). What are the keys to a longer, happier life? Answers from five decades of health psychology research. Social Science \& Medicine, 196, 218-226. http://dx.doi.org/10.1016/j.socscimed.2017.11.001

Joussemet, M., Landry, R., \& Koestner, R. (2008). A self-determination theory perspective on parenting. Canadian Psychology, 49, 194-200. http://dx.doi.org/10.1037/a0012754

Jungert, T., Landry, R., Joussemet, M., Mageau, G. A., Gingras, I., \& Koestner, R. (2015). Autonomous and Controlled Motivation for Parenting: Associations with Parent and Child Outcomes. Journal of Child and Family Studies, 24, 1932-1942. http://dx.doi.org/10.1007/s10826-014-9993-5

Koestner, R., Ryan, R. M., Bernieri, F., \& Holt, K. (1984). Setting limits on children's behavior: The differential effects of controlling versus informational styles on intrinsic motivation and creativity. Journal of Personality, 52, 233-248. http://dx.doi.org/10.1111/j.1467-6494.1984.tb00879.x

Kok, G., Gottlieb, N. H., Peters, G.-J. Y., Mullen, P. D., Parcel, G. S., Ruiter, R. A. C., . . Bartholomew, L. K. (2016). A taxonomy of behavior change methods: An intervention mapping approach. Health Psychology Review, 10, 297-312. http://dx.doi.org/10.1080/17437199.2015.1077155

Larsen, K. R., Michie, S., Hekler, E. B., Gibson, B., Spruijt-Metz, D., Ahern, D., . . Moser, R. P. (2016). Behavior change interventions: The potential of ontologies for advancing science and practice. Journal of Behavioral Medicine, 40, 6-22.

http://dx.doi.org/10.1007/s10865-016-9768-0 
Li, Y., Pan, A., Wang, D. D., Liu, X., Dhana, K., Franco, O. H., . . Hu, F. B. (2018). Impact of healthy lifestyle factors on life expectancies in the US population. Circulation. http://dx.doi.org/10.1161/CIRCULATIONAHA.117.032047

Lonsdale, C., Lester, A., Owen, K. B., White, R. L., Peralta, L., Kirwan, M., . . Lubans, D. R. (2019). An internet-supported school physical activity intervention in low socioeconomic status communities: Results from the Activity and Motivation in Physical Education (AMPED) cluster randomised controlled trial. British Journal of Sports Medicine, 53, 341-347. http://dx.doi.org/10.1136/bjsports-2017-097904

Markland, D., Ryan, R. M., Tobin, V. J., \& Rollnick, S. (2005). Motivational interviewing and self-determination theory. Journal of Social and Clinical Psychology, 24, 811-831. http://dx.doi.org/10.1521/jscp.2005.24.6.811

McLachlan, S., \& Hagger, M. S. (2010). Effects of an autonomy-supportive intervention on tutor behaviors in a higher education context. Teaching and Teacher Education, 26, 1205-1211. http://dx.doi.org/10.1016/j.tate.2010.01.006

Michie, S., \& Abraham, C. (2008). Advancing the science of behaviour change: A plea for scientific reporting. Addiction, 103, 1409-1410. http://dx.doi.org/10.1111/j.1360$\underline{0443.2008 .02291 . x}$

Michie, S., Ashford, S., Sniehotta, F. F., Dombrowski, S. U., Bishop, A., \& French, D. P. (2011). A refined taxonomy of behaviour change techniques to help people change their physical activity and healthy eating behaviours: The CALO-RE taxonomy. Psychology \& Health, 26, 1479-1498. http://dx.doi.org/10.1080/08870446.2010.540664

Michie, S., Hyder, N., Walia, A., \& West, R. (2011). Development of a taxonomy of behaviour change techniques used in individual behavioural support for smoking cessation. Addictive Behaviors, 36, 315-319. http://dx.doi.org/10.1016/j.addbeh.2010.11.016 
Michie, S., \& Johnston, M. (2017). Optimising the value of the evidence generated in implementation science: The use of ontologies to address the challenges. Implementation Science, 12, 131. http://dx.doi.org/10.1186/s13012-017-0660-2

Michie, S., Johnston, M., Abraham, C., Lawton, R., Parker, D., \& Walker, A. (2005). Making psychological theory useful for implementing evidence based practice: A consensus approach. Quality and Safety in Health Care, 14, 26-33.

http://dx.doi.org/10.1136/qshc.2004.011155

Michie, S., Richardson, M., Johnston, M., Abraham, C., Francis, J., Hardeman, W., . . Wood, C. E. (2013). The Behavior Change Technique Taxonomy (v1) of 93 Hierarchically Clustered Techniques: Building an International Consensus for the Reporting of Behavior Change Interventions. Annals of Behavioral Medicine, 46, 81-95. http://dx.doi.org/10.1007/s12160-013-9486-6

Michie, S., Wood, C. E., Johnston, M., Abraham, C., Francis, J., \& Hardeman, W. (2015). Behaviour change techniques: The development and evaluation of a taxonomic method for reporting and describing behaviour change interventions (a suite of five studies involving consensus methods, randomised controlled trials and analysis of qualitative data). Health Technology Assessment, 19, 99. http://dx.doi.org/10.3310/hta19990

Ng, J. Y. Y., Ntoumanis, N., Thøgersen-Ntoumani, C., Deci, E. L., Ryan, R. M., Duda, J. L., \& Williams, G. C. (2012). Self-determination theory applied to health contexts. Perspectives on Psychological Science, 7, 325-340. $\underline{\text { http://dx.doi.org/10.1177/1745691612447309 }}$

Ntoumanis, N., Pensgaard, A.-M., Martin, C., \& Pipe, K. (2004). An idiographic analysis of amotivation in compulsory school physical education. Journal of Sport and Exercise Psychology, 26, 197-214. http://dx.doi.org/10.1123/jsep.26.2.197

Ntoumanis, N., Quested, E., Reeve, J., \& Cheon, S. H. (2018). Need supportive communication: Implications for motivation in sport, exercise, and physical activity. In 
B. Jackson, J. A. Dimmock \& J. Compton (Eds.), Persuasion and communication in sport, exercise, and physical activity (pp. 155-169). Abingdon, UK: Routledge.

OSBBR. (2016). Strategic plan 2017-2021: Healthier lives through behavioral and social sciences. Bethesda, MD: Office of Behavioral and Social Sciences Research, National Institutes of Health.

Patall, E. A., Cooper, H., \& Robinson, J. C. (2008). The effects of choice on intrinsic motivation and related outcomes: A meta-analysis of research findings. Psychological Bulletin, 134, 270-300. http://dx.doi.org/10.1037/0033-2909.134.2.270

Patrick, H., Resnicow, K., Teixeira, P. J., \& Williams, G. C. (2013). Communication skills to elicit physical activity behavior change: How to talk to the client. In C. R. Nigg (Ed.), ACSM's behavioral aspects of physical activity and exercise (pp. 129-151).

Philadelphia, PA: Lippincott Williams \& Wilkins.

Patrick, H., \& Williams, G. C. (2012). Self-determination theory: Its application to health behavior and complementarity with motivational interviewing. International Journal of Behavioral Nutrition and Physical Activity, 9, 18. http://dx.doi.org/10.1186/1479-5868$\underline{9-18}$

Peters, G.-J. Y., de Bruin, M., \& Crutzen, R. (2015). Everything should be as simple as possible, but no simpler: Towards a protocol for accumulating evidence regarding the active content of health behaviour change interventions. Health Psychology Review, 9, 1-14. http://dx.doi.org/10.1080/17437199.2013.848409

Pihu, M., Hein, V., Koka, A., \& Hagger, M. S. (2008). How students' perceptions of teacher's autonomy-supportive behaviours affect physical activity behaviour: An application of trans-contextual model. European Journal of Sport Science, 8, 193-204. http://dx.doi.org/10.1080/17461390802067679 
Reeve, J., \& Jang, H. (2006). What teachers say and do to support students' autonomy during a learning activity. Journal of Educational Psychology, 98, 209-218. http://dx.doi.org/10.1037/0022-0663.98.1.209

Reeve, J., Jang, H., Hardre, P., \& Omura, M. (2002). Providing a rationale in an autonomysupportive way as a strategy to motivate others during an uninteresting activity. Motivation and Emotion, 26, 183-207. http://dx.doi.org/10.1023/a:1021711629417

Reeve, J., Vansteenkiste, M., Assor, A., Ahmad, I., Cheon, S. H., Jang, H., . . Wang, C. K. J. (2014). The beliefs that underlie autonomy-supportive and controlling teaching: A multinational investigation. Motivation and Emotion, 38, 93-110. http://dx.doi.org/10.1007/s11031-013-9367-0

Rothman, A. J., Gollwitzer, P. M., Grant, A. M., Neal, D. T., Sheeran, P., \& Wood, W. (2015). Hale and hearty policies: How psychological science can create and maintain healthy habits. Perspectives on Psychological Science, 10, 701-705. http://dx.doi.org/10.1177/1745691615598515

Ryan, R. M., \& Deci, E. L. (2006). Self-regulation and the problem of human autonomy: Does psychology need choice, self-determination, and will? Journal of Personality, 74, 15571586. http://dx.doi.org/10.1111/j.1467-6494.2006.00420.x

Ryan, R. M., \& Deci, E. L. (2017). Self-determination theory: Basic psychological needs in motivation, development and wellness. New York, NY: Guildford Press.

Ryan, R. M., Patrick, H., Deci, E. L., \& Williams, G. C. (2008). Facilitating health behaviour change and its maintenance: Interventions based on self-determination theory. European Health Psychologist, 10, 2-5.

Sheeran, P., Klein, W. M. P., \& Rothman, A. J. (2017). Health behavior change: Moving from observation to intervention. Annual Review of Psychology, 68, 573-600 http://dx.doi.org/10.1146/annurev-psych-010416-044007 
Sheldon, K. M., \& Elliot, A. J. (1998). Not all personal goals are personal: Comparing autonomous and controlled reasons as predictors of effort and attainment. Personality and Social Psychology Bulletin, 24, 546-557.

http://dx.doi.org/10.1177/0146167298245010

Sheldon, K. M., Elliot, A. J., Kim, Y., \& Kasser, T. (2001). What is satisfying about satisfying events? Testing 10 candidate psychological needs. Journal of Personality and Social Psychology, 80, 325-339. http://dx.doi.org/10.1037//0022-3514.80.2.325

Sheldon, K. M., Elliot, A. J., Ryan, R. M., Chirkov, V., Kim, Y., Wu, C., . . . Sun, Z. (2004). Self-concordance and subjective well-being in four cultures. Journal of Cross-Cultural Psychology, 35, 209-233. http://dx.doi.org/10.1177/0022022103262245

Sierens, E., Vansteenkiste, M., Goossens, L., Soenens, B., \& Dochy, F. (2009). The synergistic relationship of perceived autonomy support and structure in the prediction of selfregulated learning. British Journal of Educational Psychology, 79, 57-68. http://dx.doi.org/doi:10.1348/000709908X304398

Silva, M. N., Marques, M. M., \& Teixeira, P. J. (2014). Testing theory in practice: The example of self-determination theory-based interventions. European Health Psychologist, 16, 171-180.

Sparks, C., Dimmock, J. A., Lonsdale, C., \& Jackson, B. (2016). Modeling indicators and outcomes of students' perceived teacher relatedness support in high school physical education. Psychology of Sport and Exercise, 26, 71-82.

http://dx.doi.org/10.1016/j.psychsport.2016.06.004

Sparks, C., Lonsdale, C., Dimmock, J. A., \& Jackson, B. (2017). An intervention to improve teachers' interpersonally involving instructional practices in high school physical Education: Implications for student relatedness support and in-class experiences. Journal of Sport and Exercise Psychology, 39, 120-133.

http://dx.doi.org/10.1123/jsep.2016-0198 
Su, Y. L., \& Reeve, J. (2011). A meta-analysis of the effectiveness of intervention programs designed to support autonomy. Educational Psychology Review, 23, 159-188. http://dx.doi.org/10.1007/s10648-010-9142-7

Teixeira, P. J., Carraca, E., Markland, D. A., Silva, M., \& Ryan, R. M. (2012). Exercise, physical activity, and self-determination theory: A systematic review. International Journal of Behavioral Nutrition and Physical Activity, 9, 78.

http://dx.doi.org/10.1186/1479-5868-9-78

Tessier, D., Sarrazin, P., \& Ntoumanis, N. (2008). The effects of an experimental programme to support students' autonomy on the overt behaviours of physical education teachers. European Journal of Psychology of Education, 23, 239.

http://dx.doi.org/10.1007/bf03172998

Tessier, D., Sarrazin, P., \& Ntoumanis, N. (2010). The effect of an intervention to improve newly qualified teachers' interpersonal style, students motivation and psychological need satisfaction in sport-based physical education. Contemporary Educational Psychology, 35, 242-253. http://dx.doi.org/10.1016/j.cedpsych.2010.05.005

The US Burden of Disease Collaborators. (2018). The state of US health, 1990-2016: Burden of diseases, injuries, and risk factors among US States. JAMA, 319, 1444-1472. http://dx.doi.org/10.1001/jama.2018.0158

Ueda, P., Lung, T. W.-C., Lu, Y., Salomon, J. A., Rahimi, K., Clarke, P., \& Danaei, G. (2018). Treatment gaps and potential cardiovascular risk reduction from expanded statin use in the US and England. PLOS ONE, 13, e0190688. http://dx.doi.org/10.1371/journal.pone.0190688

Vansteenkiste, M., \& Ryan, R. M. (2013). On psychological growth and vulnerability: Basic psychological need satisfaction and need frustration as a unifying principle. Journal of Psychotherapy Integration, 23, 263-280. http://dx.doi.org/10.1037/a0032359 
Vansteenkiste, M., \& Sheldon, K. M. (2006). "There's nothing more practical than a good theory": Integrating motivational interviewing and self-determination theory. British Journal of Clinical Psychology, 44, 63-82. http://dx.doi.org/10.1348/014466505x34192

Vansteenkiste, M., Simons, J., Lens, W., \& Sheldon, K. M. (2004). Motivating learning, performance, and persistence: The synergistic effects of intrinsic goal contents and autonomy-supportive contexts. Journal of Personality and Social Psychology, 87, 246260. http://dx.doi.org/10.1037/0022-3514.87.2.246

Vansteenkiste, M., Simons, J., Soenens, B., \& Lens, W. (2004). How to become a persevering exerciser? Providing a clear, future intrinsic goal in an autonomy-supportive way. Journal of Sport and Exercise Psychology, 26, 232-249.

http://dx.doi.org/10.1123/jsep.26.2.232

Vansteenkiste, M., Williams, G., \& Resnicow, K. (2012). Toward systematic integration between self-determination theory and motivational interviewing as examples of topdown and bottom-up intervention development: Autonomy or volition as a fundamental theoretical principle. International Journal of Behavioral Nutrition and Physical Activity, 9, 23. http://dx.doi.org/10.1186/1479-5868-9-23

Williams, G. C., \& Deci, E. L. (1996). Internalization of biopsychosocial values by medical students: A test of self-determination theory. Journal of Personality and Social Psychology, 70, 767-779. http://dx.doi.org/10.1037/0022-3514.70.4.767

Williams, G. C., McGregor, H. A., Sharp, D., Kouides, R. W., Levesque, C. S., Ryan, R. M., \& Deci, E. L. (2006). A self-determination multiple risk intervention trial to improve smokers' health. Journal of General Internal Medicine, 21, 1288-1294. http://dx.doi.org/10.1111/j.1525-1497.2006.00621.x

Williams, G. C., McGregor, H. A., Sharp, D., Levesque, C. S., Kouides, R. W., Ryan, R. M., \& Deci, E. L. (2006). Testing a self-determination theory intervention for motivating 
tobacco cessation: Supporting autonomy and competence in a clinical trial. Health Psychology, 25, 91-101. http://dx.doi.org/10.1037/0278-6133.25.1.91

Wood, A. M., Kaptoge, S., Butterworth, A. S., Willeit, P., Warnakula, S., Bolton, T., .. . Danesh, J. (2018). Risk thresholds for alcohol consumption: Combined analysis of individual-participant data for 559912 current drinkers in 83 prospective studies. The Lancet, 391, 1513-1523. http://dx.doi.org/10.1016/S0140-6736(18)30134-X

Zuroff, D. C., Koestner, R., Moskowitz, D. S., McBride, C., Marshall, M., \& Bagby, M. R. (2007). Autonomous motivation for therapy: A new common factor in brief treatments for depression. Psychotherapy Research, 17, 137-147.

http://dx.doi.org/10.1080/10503300600919380 
Table 1

Conceptual Definitions of the Three Psychological Needs from Self-Determination Theory

\begin{tabular}{ll}
\hline Psychological need & Conceptual definition \\
\hline Autonomy & The psychological need to experience self-direction and personal \\
endorsement in the initiation and regulation of one's behavior. The \\
hallmarks of autonomy need satisfaction are volitional action and \\
wholehearted self-endorsement (i.e., personal ownership) of that action. \\
The psychological need to be effective in one's interactions with the \\
environment, and it reflects the desire to extend one's capacities and skills \\
and, in doing so, to seek out optimal challenges, take them on, and exert \\
effort and strategic thinking until personal growth is experienced. \\
The psychological need to establish close emotional bonds and attachments \\
with other people, and it reflects the desire to be emotionally connected to \\
and interpersonally involved in warm relationships. The hallmarks of \\
relatedness need satisfaction are feeling socially connected and being \\
actively engaged in both the giving and receiving of care and benevolence \\
to the significant people in one's life.
\end{tabular}

Note. Conceptual definitions are based on Ryan and Deci (2017). 


\section{Table 2}

Steps in the Development of the Classification of Motivation and Behavior Change Techniques (MBCTs)

\begin{tabular}{ll}
\hline Steps & Methods \\
$\begin{array}{l}\text { 1. Development of the first } \\
\text { list of MBCTs }\end{array}$ & $\begin{array}{l}\text { Content analysis from published SDT interventions; Group } \\
\text { discussions within core research team }\end{array}$ \\
$\begin{array}{l}\text { 2. Consensus exercise - } \\
\text { Round 1 }\end{array}$ & $\begin{array}{l}\text { Feedback from 8 experts on clarity and content of the } \\
\text { MBCTs; Group discussions within core research team }\end{array}$ \\
$\begin{array}{l}\text { 3. Consensus exercise - } \\
\text { Round 2 }\end{array}$ & $\begin{array}{l}\text { Online expert feedback consensus (N=18) on the need- } \\
\text { sensitivity, essentiality and uniqueness of each MBCT }\end{array}$ \\
$\begin{array}{l}\text { 4. Discussion and refinement } \\
\text { of the MBCTs }\end{array}$ & $\begin{array}{l}\text { Core research team members discussed and refined the } \\
\text { MBCTs, based on the results from step 3 }\end{array}$ \\
$\begin{array}{l}\text { 5. Consensus exercise - } \\
\text { Round 3 }\end{array}$ & $\begin{array}{l}\text { Online expert feedback consensus with same poof of } \\
\text { experts, for 1) MBCTs which didn't reach a sufficient } \\
\text { inter-rater agreement; 2) new MBCTs }\end{array}$ \\
$\begin{array}{l}\text { 6. Revision and finalization of } \\
\text { the MBCTs }\end{array}$ & $\begin{array}{l}\text { MBCTs, based on the results from step 5 } \\
\text { M. Mapping MBCTs to the }\end{array}$ \\
$\begin{array}{l}\text { Taxonomy of Behavior } \\
\text { Change Techniques v1 }\end{array}$ & $\begin{array}{l}\text { The core study team members compared the final list of } \\
\text { MBCTs with the Taxonomy of Behavior Change } \\
\text { Techniques v1 }\end{array}$ \\
\hline
\end{tabular}


Table 3

Classification of Motivation and Behavior Change Techniques

\begin{tabular}{lll}
\hline Label Definition & Function description \\
\hline
\end{tabular}

Autonomy-Support Techniques

MBCT1. Elicit perspectives on condition or behavior

MBCT2. Prompt identification of sources of pressure for behavior change

MBCT 3. Use noncontrolling, informational language

MBCT 4. Explore life aspirations and values

MBCT 5. Provide a meaningful rationale

MBCT 6. Provide choice
Encourage exploration and sharing of perspectives on current behavior (e.g., causes, perpetuating factors etc.).

Prompt identification of possible sources of external (or partially internalized) pressures and expectations, and explore how they may relate to client's desired goals and outcomes.

Use informational, non-judgmental language that conveys freedom of choice, collaboration, and possibility when communicating (avoiding constraining, pressuring, or guilt-inducing language). For example, use "might" or "could" instead of "should" and "must".

Prompt identification and listing of important life aspirations, values, and/or long-term interests and explore how changes in behavior (or maintaining the status quo) could be linked to them.

Prompt client to identify rationale for behavior change and its maintenance that is tailored, explanatory, and personally meaningful or valuable.

Provide opportunities to make choices from a collaboratively-devised menu of behavioral options and autonomous goals. It includes the decision not to change, delay change, select focus/intensity of change, personally endorsed intrinsic goals and standards for success, including the timing or pace for certain outcomes.

\begin{abstract}
Allows exploration of behavior in more depth (self-knowledge), which can inform the program and personal choices. Explores locus of causality and potential sources of external/introjected regulation and its consequences.
\end{abstract}

Avoids being a source of pressure or creating internal pressure, countering external locus of causality for actions.

Explores integrity and internal coherence between aspirations, values, and goals/behaviors, which can sustain autonomous regulation.

Highlights and reinforces motives/reasons that could form the basis of autonomous motivation.

Promotes personal input and ownership over behavior change and responsibility through choice. 
MBCT 7. Encourage the person to experiment and selfinitiate the behavior
Prompt the person to experiment and selfinitiate (new) target behavior that could be fun and enjoyable, is experienced as positive challenge, opportunity for learning or personal expression, and/or are associated with skill development, all of which provide experiential / immediate positive reinforcement".

Relatedness-support techniques

MBCT 8.

Acknowledge and respect perspectives and feelings

MBCT 9. Encourage asking of questions

MBCT 10. Show unconditional regard

MBCT 11.

Demonstrate/show interest in the person

MBCT 12. Use empathic listening

MBCT 13. Providing opportunities for ongoing support

MBCT 14. Prompt identification and
Provide statements of empathy and acknowledgment of the person's perspective, conflicts/ambivalence, distress and negative affect (fear, confusion, etc.) and also expression of positive feelings when communicating with client (concerning the target behavior, treatment, or other related matters).

Prompt the client to pose questions regarding their goals/behavioral progress.

Express positive support regardless of success or failure.

Provide statements of interest and curiosity about the person's thoughts and perceptions, personal history and background, social context, life events, etc. when communicating.

Demonstrate attentiveness to the client's responses (e.g., stay silent to allow the person to complete sentences), and provide reflective and summary statements when appropriate (directed at affect or content) when communicating. Prompt permission to provide new information, guidance or advice.

Offer the person an appropriate venue and means to contact you in the event of difficulties or questions during the behavior change process.

Prompt identification of sources of support for behavior change (if relevant),
Supports autonomous action via intrinsic motivation.
Indicates attention and respect for the person's attitudes, thoughts perceptions, and feelings, which creates an accepting and warm social environment.

Creates an open and collaborative relation that promotes trust.

Demonstrates unconditional respect, care and support and promotes warm social environment.

Displays involvement, indicates to the person that their experiences and input are valued.

Creates open, collaborative relation; promotes trust; Displays respect for the person.

Shows care and personal involvement.

Includes strategies that will help in feeling 
seek available social support acknowledge challenges in recruiting adequate support (autonomous vs controlled), and promote effective ways of seeking positive support.

confident to overcome potential challenges and meet behavioral goal (e.g., information about available programs, active involvement of others such as family members).

Increases confidence and reinforces existing skills.

\author{
MBCT 15. Address \\ obstacles for change \\ MBCT 16. Clarify \\ expectations
}

MBCT 17. Assist in setting optimal challenge

MBCT 18. Offer
constructive, clear,
and relevant
feedback

MBCT 19. Help develop a clear and concrete plan of action

MBCT 20. Promote self-monitoring

MBCT 21. Explore ways of dealing with pressure
Prompt identification of likely barriers to behavior change, based on previous attempts, and explore how to overcome them (e.g., what may have worked in the past).

Prompt statements of client's own expectations in terms of behavior change (e.g., identify a clear goal or learning objective), both its experiential elements (process) as well as outcomes.

Assist in identification of goals that are realistic, meaningful challenging, and achievable.

Provide relevant, tailored, non-evaluative feedback on goal/behavioral progress. This can include specific, process-focused feedback.

Develop and provide summary of action plan to work toward a behavioral goal.

Prompt monitoring of progress, skill level, or performance such as suggesting options for monitoring tools/means and metrics for success, including steps in the direction of behavior change.

Provide information to manage and limit effects of pressuring contingencies that would undermine competence such as extrinsic rewards, criticism, negative feedback.
Provides structure and minimizes future failure (and perceived incompetence).

Provides structure and minimizes future failure (and perceived incompetence)

Provides encouragement and information to guide future behavior.

Provides structure, increases confidence, and minimizes future failure (and perceived incompetence). Provides structuring information that reinforces success and self-awareness.

Increase confidence to deal with sources of controlling pressure from others and themselves.

Note. Reference to "the person" in technique descriptions refers to the individual or group whose behavior is to be changed (e.g., a client, patient or participant). MBCT = Motivation and behavior change technique. 
Figure 1. A basic process model of self-determination theory in health contexts.

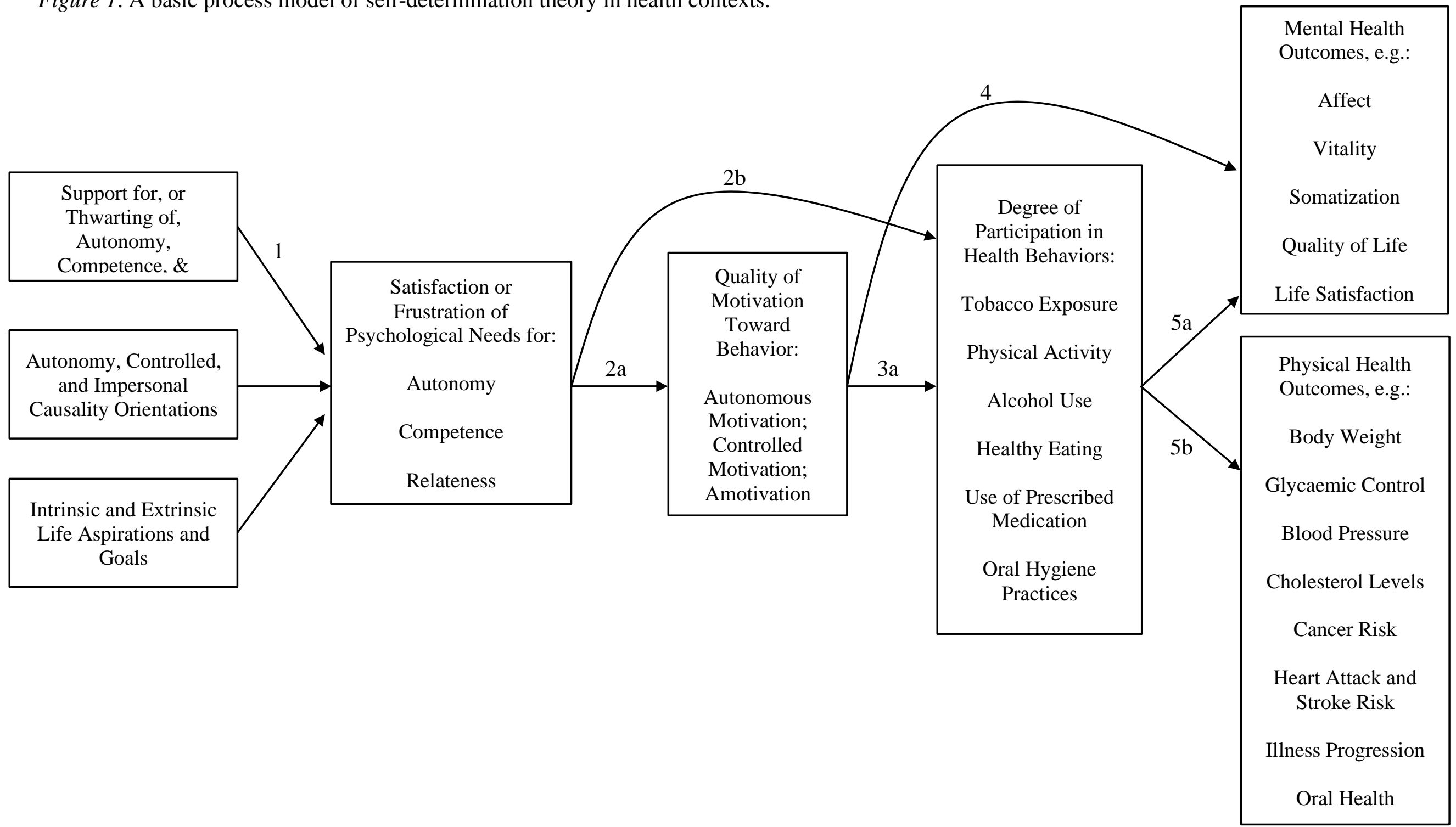

